\title{
Historical Changes in Abundance of Floating-Leaf and Emergent Vegetation in Minnesota Lakes
}

\author{
PAUL RADOMSKI* \\ Minnesota Department of Natural Resources, 1601 Minnesota Drive, Brainerd, Minnesota 56401, USA
}

\begin{abstract}
To assess the consequences of shoreline development, whole-lake vegetation abundance of dense floating-leaf and emergent vegetation in 100 north-central Minnesota lakes was estimated from aerial photographs for selected years between 1939 and 2003. Lakes were randomly selected from three shoreland development classifications, which define statewide minimum shoreline development standards for Minnesota. The three classes, in order of increasing restrictions for development, are general development, recreational development, and natural environment. Image analysis techniques were used to estimate vegetation abundance (percent cover). Shoreline development varied by shoreland development class. Floating-leaf and emergent vegetative cover (percent of lake surface area) was significantly affected by development. Increases in shoreline development, indexed by dock sites per shoreline kilometer, reduced plant cover. A linear mixed-effects model estimated that in 2003, the mean floating-leaf and emergent vegetation cover loss from development was $6 \%$ for natural-environment lakes, $14 \%$ for recreationaldevelopment lakes, and $17 \%$ for general-development lakes. Total vegetation cover loss for north-central Minnesota lakes was estimated at $15 \%$. Shoreline regulatory policies may need to be changed or riparian owner incentive programs added to address cumulative impacts to fish and wildlife habitat.
\end{abstract}

Increases in shoreland development are changing lake ecosystems. Development pressure is increasing, as evidenced by increases in the number of dwellings per lake each year (Kelly and Stinchfield 1998). Human habitation along the shore has a cumulative effect on fish and wildlife habitat, water quality, and biota of lake ecosystems (Engel and Pederson 1998). Christensen et al. (1996) found a significantly lower amount of coarse woody debris along developed shorelines in Wisconsin and Michigan, predicting that recent losses in developed lakes will affect littoral communities for about two centuries. Meyer et al. (1997) concluded that housing development along shores of northern Wisconsin lakes dramatically altered native vegetation, especially shrubs, and reduced frog populations. Elias and Meyer (2003) found that for upland, shoreline, and shallow-water areas, the mean number of plant species and the percent of native species were both greater at undeveloped sites than along developed Wisconsin lakeshores. Jennings et al. (1996) noted changes in nearshore substrate composition in Wisconsin lakes that they attributed to human activity. In an Iowa lake, Byran and Scarnecchia (1992) found significantly lower aquatic macrophyte abundance in developed shorelines than in undeveloped shorelines. Jennings et al. (2003) also found that the amounts of littoral wood remains and emergent and

*E-mail: paul.radomski@dnr.state.mn.us

Received May 26, 2005; accepted February 15, 2006 Published online November 20, 2006 floating-leaf vegetation were lower at developed sites and at lakes with greater development density.

Some consequences of human activities along shorelines have been difficult to document; many studies rely on comparisons between developed and undeveloped shoreland. In a comparison of vegetation abundance along undeveloped and developed shorelines for 44 Minnesota lakes, Radomski and Goeman (2001) estimated a 20-28\% loss of emergent and floating-leaf coverage from human development. However, comparisons of vegetation differences among sites and calculations of habitat loss could be confounded by human behavior. For example, if people seek to inhabit developable lakeshore lots with a lower abundance of emergent or floating-leaf vegetation, then estimates of habitat loss or consequences of development could be inflated. In addition, abundance of lake flora is not static, so losses could be larger or smaller depending on annual lake productivity and long-term trends. Historical evidence of whole-lake vegetative loss in relation to development is needed to substantiate this work.

The objective of this study was to determine the historical abundance of dense floating-leaf and emergent vegetation stands for numerous north-central Minnesota lakes across a lakeshore development gradient. In Minnesota, aerial photographs have been taken to gather forest inventory data about every 10 years since 1939. The goal was to use these photographs to (1) derive a sufficient number of whole-lake estimates of vegetation abundance, (2) 
detect temporal variability or trends in abundance, and (3) determine whether human lakeshore development caused a significant loss of fish and wildlife habitat.

\section{Methods}

Study lakes.-Stratified random sampling was used to select 100 north-central Minnesota lakes from a pool of 3,367 lakes greater than 4 ha; stratification involved three shoreland development classes from which approximately equal, simple random samples were drawn. Mine pit lakes and lakes greater than 405 ha were excluded so as to limit other confounding influences and to reduce image processing difficulties. Statewide minimum shoreline standards affect a large percentage of Minnesota's lakes. These standards, first established in the 1970s by the Minnesota Department of Natural Resources (MNDNR), set guidelines for the use and development of shoreland property, including a sanitary code, minimum lot size, minimum water frontage, building setbacks, building heights, and subdivision regulations (MNDNR 1989). The standards followed a tiered (based on development restriction) approach in establishing the three shoreland development classes: general development, recreational development, and natural environment (from least to most restrictive). General-development lakes are generally large, deep lakes or lakes of varying sizes and depths that have high levels and mixes of shoreland development. Recreational-development lakes are generally medium-sized lakes of varying depths and shapes, and they often are characterized by moderate levels of recreational use and shoreland development. Natural-environment lakes are generally small, often shallow lakes with limited capacities for assimilating the impacts of development and recreational use. These lakes are typically lightly developed. Of the 3,367 lakes in this five-county area of north-central Minnesota, 3\% are classified as general development (1,627 shoreline kilometers [skm]), $14 \%$ as recreational development $(3,383 \mathrm{skm})$, and $60 \%$ as natural environment $(>4,000$ $\mathrm{skm})$; the remainder are small water bodies that are currently unclassified. Of the 2,027 naturalenvironment lakes in this area, only 392 had limnological data available from fisheries surveys. A random sample of lakes from this 392-lake subset was used; thus, it was assumed that the results may be generalized only to lakes with fish.

Macrophyte quantification.-Existing aerial photographs for each lake were acquired; most photographs were taken during the summer or fall of 1939,1955 , 1960, 1969, 1978, 1989, 1996, and 2003 (90\% of the photographs were from these or adjacent years). For some lakes, the full series of eight images were not available or usable. The film types included mostly black and white, but color infrared was used for the late-1990s photos and natural color was used for the 2003 images. In 1996, photos were taken later in the year after some plant senescence and dock removal had occurred. The timing of photographs was categorized into three groups: before August 1 (before peak biomass), August 1 to September 15 (generally peak biomass), and after September 15 (period of senescence). The scale of the photos was $1: 20,000$ or 1:15,840 (University of Minnesota 2003), except for the 2003 images, which had a scale of 1:40,000 (Farm Services Agency 2003).

Photographs (except the 2003 images) were digitized using a scanner. Photos were scanned at a density of 629.9 pixels/cm into the three-color-channel tagged image file format (TIFF). At a 1:15,840 scale, this means the actual ground area covered per pixel was 632 $\mathrm{cm}^{2}$. The 2003 georeferenced raster images (GeoTIFF) were obtained from county mosaics in MrSID (multiresolution seamless image database) format from the Minnesota Land Management Information Center via GeoExpress software (Lizardtech 2003). These images had a 1-m ground sample distance. The resulting lake photographs were of varying quality, yet they appeared to provide satisfactory images for estimating floatingleaf and emergent vegetative cover from moderately dense to very dense stands.

Images were processed and analyzed using image analysis software. First, the number of boat docking sites or piers on each lake was counted and used as an index of development. Second, masking out the terrestrial area created a lake-only image, which was used for further processing. Each three-channel color pixel in the lake image was classified within MultiSpec software using the unsupervised classification ISODATA iterative clustering algorithm (Richards 1993). This algorithm, which classifies image pixels based on spectral properties, uses principal components and an iterative process that associates each pixel with a cluster center located at the smallest Euclidean distance to the pixel. The goal of the clustering was to obtain about 10 clusters. The percent of pixels classified as aquatic vegetation, both floating-leaf and emergent, was determined with MultiSpec for each lake image. Lake images with excess glitter or specular reflection on the water surface or that were taken early in the growing season were not processed. Images were processed to determine the percent of lake surface and percent of littoral area that was covered with aquatic vegetation $(N$ $=729$ ). The littoral area was defined as the portion of the lake that was less than $4.6 \mathrm{~m}$ deep according to the most recent MNDNR lake sounding map.

Other lake data were also obtained from the MNDNR. The estimated shoreline length for each lake 
was used to calculate dock site densities. Mean total alkalinity and Secchi disk readings for each lake were calculated from lake survey data collected from the 1940s to 1997. Because Moyle $(1945,1956)$ noted that alkalinity was an important factor in plant occurrence in Minnesota, lakes were grouped into three alkalinity categories $(<40,40-90$, and $>90 \mathrm{mg} / \mathrm{L})$. Carlson's (1977) trophic status index (TSI) was calculated for each lake from mean Secchi disk transparency (SDT, m) using the equation

$$
T S I=60-14.41 \log _{e}(S D T)
$$

A 10-unit increase in TSI generally corresponds to a halving of Secchi depth and a doubling of phosphorus concentration. Lakes were grouped into three TSI categories: oligotrophic-mesotrophic (TSI $=30-40)$, mesotrophic (40-50), and mesotrophic-eutrophic $(>50)$.

Statistical analysis.-First, correlation coefficients for the percent vegetative cover (percentage of lake area, arcsine-square-root transformed) and time (year of photograph) were calculated for each lake. Significant differences between mean correlation coefficients by shoreland development class were tested with the Tukey-Kramer honestly significant difference (HSD) test (SAS 2002).

Second, mixed-effects models were used to test for significant fixed effects on floating-leaf and emergent vegetative cover. The general form, in the notation of Laird and Ware (1982), is

$$
y=X_{i \beta}+Z_{i} \cdot b_{i}+\varepsilon_{I},
$$

where $y$ is percent vegetative cover (percentage of lake or littoral area, arcsine-square root transformed), $X_{i \beta}$ represents the fixed effects, $Z_{i} \cdot b_{i}$ represents the random effects, and $\varepsilon_{i}$ represents the residual errors. Fixed effects are parameters associated with an entire population or from observations taken on all treatments of interest; random effects are associated with individual experimental units drawn at random from a population. A repeated-measures analysis was conducted using the nlme package (Pinheiro and Bates 2000 ) in the statistical programming language $R(R$ Development Core Team 2005). Models were fit using restricted maximum likelihood, except when comparing models of different fixed-effect structure with likelihood ratio tests, in which case models were fit using maximum likelihood. One-hundred lakes had up to eight estimates of vegetative cover, and therefore "lake" was used as the repeated-measures variable; lakes were modeled as random effects. The analysis assumed that data from different lakes were statistically independent. The repeated-measures strategy followed
Wolfinger and Chang (1995), who suggested that where fixed effects are selected, (1) different variance or correlation structures are selected and tested, (2) fixed effects are tested, and (3) inferences for fixed effects are made. The influences of time (periods 1-8), shoreland development class (general development, recreational development, and natural environment), timing of the photograph (three groups), alkalinity (three groups), and TSI (three groups) were analyzed as fixed effects and "dock sites [DS] per shoreline kilometer" (square-root transformed) was added as a linear effect. Homoscedastic within-group errors were assumed and tested against variance modeled as a power of the mean (weights $=$ varPower statement in the linear mixed effects [lme] function within nlme). Although not presented, evidence of heteroscedasticity in the within-group errors $(P<0.0001$ in likelihood ratio tests) was found, such that a model fit with variance modeled by shoreland development class appeared to be the best approach. Residual plots and quantile-quantile plots were used to assess the assumptions of the models.

After initial testing to determine significant fixed effects, a suite of 16 candidate models was developed that incorporated alkalinity, TSI, and development (DS/skm, square-root transformed) in different combinations to draw inferences on these effects and the other fixed effects. The primary hypothesis was that vegetation coverage would be lower with increasing development. Akaike's information criterion (AIC) was used to select the preferred model, and Akaike weights were used to quantify the strength of evidence for alternative models (Burnham and Anderson 2002).

To determine habitat gains or losses from development by shoreland development class, predicted mean values from the preferred model were estimated via linear combinations of treatment-level means that assumed no development (DS/skm), the mean development density, and across a range of development densities. Vegetative cover loss or the relative change in percent vegetative cover (i.e., from no development to mean development or a range of development) for each shoreland development class were then predicted with confidence intervals and were back-transformed (Zar 1999). The null hypothesis was that vegetative cover was the same across shoreland development classes and was not a function of development density. Mixed-effects models have benefits over other frequentist procedures because they use likelihood-based estimation such that all measurements for a lake are used, even when some measurements are missing for some years; these models recognize that some dependency exists between observations from the same 
lake (Pinheiro and Bates 2000). The R code for the preferred model is provided in Appendix.

\section{Results}

Development (DS/skm) varied by shoreland development class. General-development lakes have had a faster rate of development than recreational-development lakes since the 1970s, whereas natural-environment lakes remained lightly developed (Figure 1). In 2003, median development density was $1.40 \mathrm{DS} / \mathrm{skm}$ for naturalenvironment lakes, $7.04 \mathrm{DS} / \mathrm{skm}$ for recreationaldevelopment lakes, and $10.58 \mathrm{DS} / \mathrm{skm}$ for generaldevelopment lakes (Table 1). Based on DS per shoreline distance, general-development lakes had a mean lakeshore lot width of $87 \mathrm{~m}$, and the lowest average lakeshore lot width for these lakes was $43 \mathrm{~m}$. For generaldevelopment lakes, statewide minimum shoreline standards require a minimum lot width of $30 \mathrm{~m}$, suggesting that these north-central Minnesota lakes are likely to experience higher development densities in the future.

For many natural-environment lakes, the lakewide percent vegetative cover increased over time, whereas for many general-development lakes this percentage declined over time (Figure 2). Correlation coefficients for these two classes were significantly different (Tukey-Kramer HSD test: $P<0.05$; Figure 2).

Initial testing of mixed-effects models suggested that time, the two-way interaction between time and shoreland development class, and timing of photographs within the year were important predictors of plant cover. In addition, the highest-ranked mixedeffects models for lakewide vegetative cover and littoral vegetative cover included development effect (DS/skm), suggesting that development was an important predictor of plant cover (Table 2). The sum of Akaike weights for models that included a development effect was 0.83 for lake vegetative cover models and 0.76 for littoral vegetative cover. Trophic status index was more important as a factor for lake vegetative cover, whereas alkalinity appeared to be more important as a factor for littoral vegetative cover.

Mixed-effects models indicated that floating-leaf and emergent vegetative cover (percentage of lake surface, transformed) was significantly affected $(P<0.10)$ by development ("docks" variable; Table 3 ). Increases in shoreline development (DS/skm) reduced plant cover. For estimating vegetative cover loss, the preferred model indicated by the lowest AIC score was a linear mixed-effects model containing time, shoreland development class, timing of photograph within the year, and the time $\times$ shoreland development class interaction as fixed effects and DS per shoreline kilometer (transformed) as a linear effect (Table 3, model 2). Because two-way interactions between shoreland development

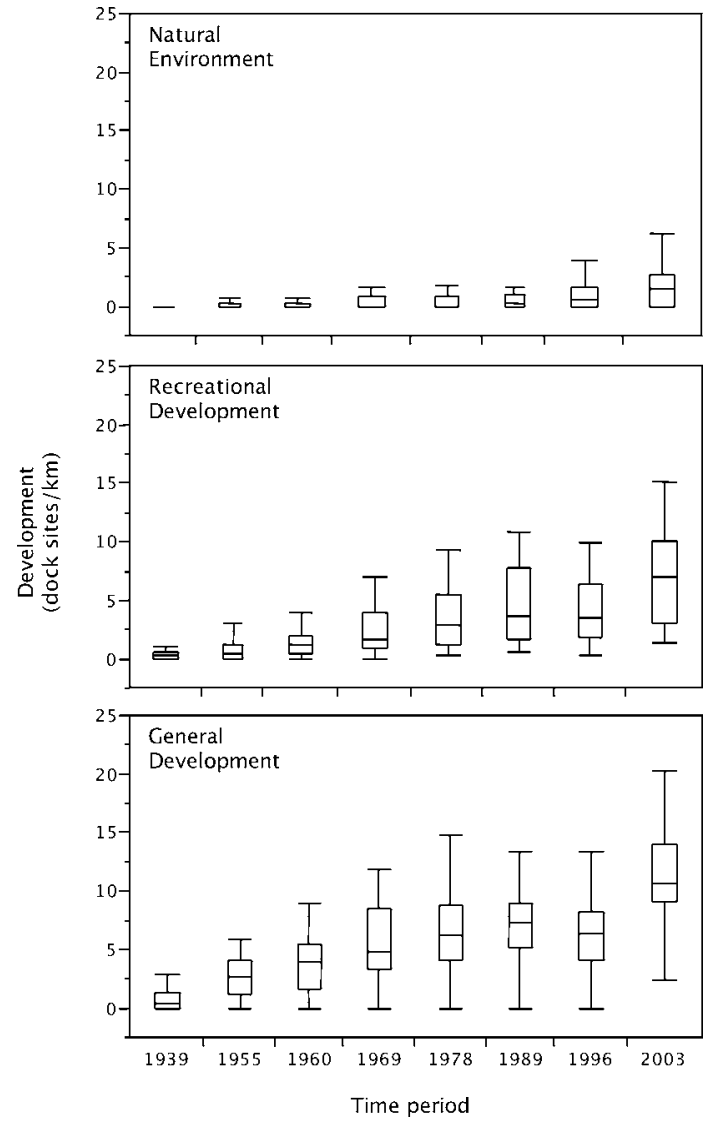

FIGURE 1.-Shoreline development in north-central Minnesota lakes belonging to three shoreland development classes, 1939-2003. The box is the interquartile range. The vertical line endpoints are not longer than 1.5 times the interquartile range, and the line within the box is the median. Periods are labeled with the modal year.

class and time were observed, mean comparisons were conducted according to the two-way interaction. This linear mixed-effects model estimated that the mean floating-leaf and emergent vegetation cover loss in 2003 from lakeshore development was $6 \%$ for naturalenvironment lakes, $14 \%$ for recreational-development lakes, and $17 \%$ for general-development lakes (Figure 3 ). The weighted average vegetation cover loss in 2003, weighted by surface area in each shoreland development class, was $15 \%$ for the five-county north-central Minnesota area. Allowing full development of naturalenvironment lakes at the shoreland standard of a $61-\mathrm{m}$ lot width predicted an $18 \%$ reduction in floating-leaf and emergent plant coverage (Figure 4). Full development of a recreational-development lake at the shoreland standard lot width of $46 \mathrm{~m}$ predicted a $26 \%$ reduction of plant cover. Full development of general- 
TABlE 1.-Median, mean, and standard deviation of north-central Minnesota lake attributes for three shorelanddevelopment classes.

\begin{tabular}{|c|c|c|c|}
\hline \multirow[b]{2}{*}{ Variable } & \multicolumn{3}{|c|}{ Shoreland development class } \\
\hline & $\begin{array}{c}\text { Natural } \\
\text { environment }\end{array}$ & $\begin{array}{l}\text { Recreational } \\
\text { development }\end{array}$ & $\begin{array}{c}\text { General } \\
\text { development }\end{array}$ \\
\hline Number of lakes & 31 & 37 & 32 \\
\hline \multicolumn{4}{|c|}{ Surface Area (ha) } \\
\hline Median & 28 & 80 & 119 \\
\hline Mean & 34 & 94 & 125 \\
\hline SD & 29.15 & 54.73 & 63.05 \\
\hline \multicolumn{4}{|c|}{ Littoral area (\% lake surface area) } \\
\hline Median & 63 & 52 & 57 \\
\hline Mean & 62 & 58 & 59 \\
\hline SD & 21.42 & 22.72 & 23.90 \\
\hline \multicolumn{4}{|c|}{ Shoreline length (km) } \\
\hline Median & 2.9 & 4.8 & 5.9 \\
\hline Mean & 3.0 & 6.0 & 6.5 \\
\hline SD & 1.65 & 2.97 & 3.13 \\
\hline \multicolumn{4}{|c|}{ Total alkalinity (mg/L) } \\
\hline Median & 56.0 & 83.0 & 87.5 \\
\hline Mean & 60.1 & 85.3 & 86.0 \\
\hline SD & 47.60 & 42.23 & 24.19 \\
\hline \multicolumn{4}{|c|}{ Secchi disc (m) } \\
\hline Median & 2.7 & 3.4 & 3.3 \\
\hline Mean & 3.0 & 3.4 & 3.3 \\
\hline SD & 1.55 & 1.29 & 1.27 \\
\hline \multicolumn{4}{|c|}{ Trophic status index (TSI) } \\
\hline Median & 46 & 43 & 43 \\
\hline Mean & 46 & 43 & 44 \\
\hline SD & 7.03 & 5.72 & 6.19 \\
\hline \multicolumn{4}{|c|}{ Vegetative cover ( $\%$ lake surface area) } \\
\hline Median & 4.97 & 3.54 & 3.77 \\
\hline Mean & 6.93 & 5.02 & 5.97 \\
\hline SD & 7.26 & 5.13 & 6.51 \\
\hline Sample $(N)$ & 223 & 269 & 237 \\
\hline \multicolumn{4}{|c|}{ Vegetative cover (\% littoral area) } \\
\hline Median & 7.88 & 6.65 & 7.56 \\
\hline Mean & 13.05 & 9.44 & 10.47 \\
\hline SD & 13.94 & 9.25 & 10.10 \\
\hline$N$ & 223 & 269 & 237 \\
\hline \multicolumn{4}{|c|}{2003 Development density (dock sites/km) } \\
\hline Median & 1.40 & 7.04 & 10.58 \\
\hline Mean & 2.47 & 6.93 & 11.47 \\
\hline SD & 3.72 & 4.17 & 5.04 \\
\hline$N$ & 31 & 37 & 32 \\
\hline
\end{tabular}

development lakes at $30-\mathrm{m}$ lot widths or 32.8 homes/ $\mathrm{skm}$ was beyond the range of the data used in the model.

\section{Discussion}

Other studies have found a substantial reduction in floating-leaf and emergent vegetative cover with increasing development; this study supports those findings. Radomski and Goeman (2001), in comparing undeveloped and developed shoreline plots, estimated a 20-28\% loss of emergent and floating-leaf coverage from human development for all of Minnesota's clearwater centrarchid-walleye (Sander vitreus) lakes; for

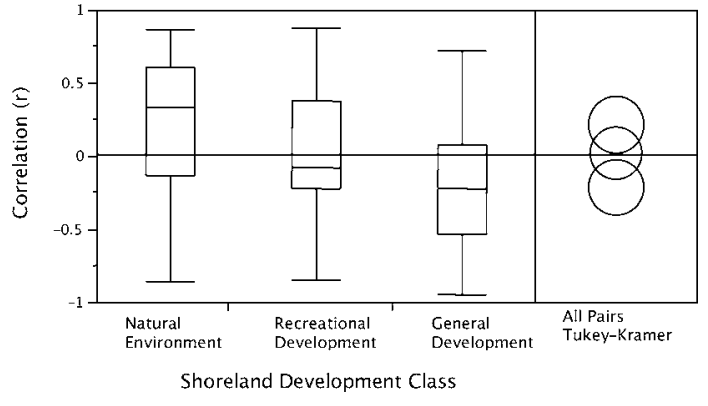

Figure 2.-Box plot of correlation coefficients $(r)$ for percent vegetative cover (percentage of lake surface area; arcsine-square-root transformed) and time (year of photograph) for north-central Minnesota lakes belonging to three shoreland development classes. The box is the interquartile range. The vertical line endpoints are not longer than 1.5 times the interquartile range, and the line within the box is the median. Significant differences in $r$ by shoreland development class were tested with Tukey-Kramer HSD tests. Circles for means that are significantly different either do not intersect or intersect only slightly; here, the mean $r$ for naturalenvironment lakes differed significantly from that of generaldevelopment lakes.

every developed shoreline plot, the reduction in vegetative cover relative to undeveloped conditions averaged 66\%. Application of the 2003 estimates of vegetation loss from the present study to the lakes in the Radomski and Goeman (2001) study (weighted by shoreland development class) produced an estimated loss of $14 \%$ for Minnesota's clear-water centrarchidwalleye lakes. This estimate differs from the $20-28 \%$ range reported by Radomski and Goeman (2001), perhaps because that study only estimated vegetative cover loss for emergent and floating-leaf vegetation within $30.6 \mathrm{~m}$ of shore and the methods allowed detection of less-dense stands of vegetation. Alternatively, the Radomski and Goeman (2001) estimate may be slightly biased upward due to people initially selecting development locations with less floating-leaf and emergent vegetation near shore. For a group of Wisconsin lakes, developed shorelines had $92 \%$ less floating-leaf cover and $83 \%$ less emergent vegetative cover than undeveloped shorelines (Meyer et al. 1997). Jennings et al. (2003) also found that emergent and floating-leaf vegetation decreased at developed sites and in lakes with greater cumulative shoreland development density. In addition, Elias and Meyer (2003) found that the mean number of plant species and the percentage of native species were greater along undeveloped shorelines than along developed shorelines.

Although people value lakes and shorelines, many people alter the shoreland and littoral area of lakes. Payton and Fulton (2004) found that 14\% of Minnesota lakeshore homeowners reported removing floating-leaf 
TABLE 2.- Suite of candidate models used to understand the relative influence of variables on dense-stand floating-leaf and emergent vegetative cover in north-central Minnesota lakes. The base model included time (periods 1-8), the two-way interaction between time and shoreland development class (general development, recreational development, and natural environment), and timing of photographs within the year as fixed effects. Added effects included alkalinity group (ALK), trophic status index (TSI), and development (docks). Akaike's information criterion (AIC) and log likelihood were estimated using maximum likelihood. Models are ranked by increasing $\mathrm{AIC}_{c}$ (AIC corrected for sample size) or decreasing Akaike weight $\left(w_{r}\right)$.

\begin{tabular}{lccccc}
\hline Additional effects & $\mathrm{df}$ & $\mathrm{log}$ likelihood & $\mathrm{AIC}_{c}$ & $\Delta \mathrm{AIC}_{c}$ & $w_{r}$ \\
\hline \multicolumn{5}{c}{ Vegetative cover } & as percentage of lake surface area \\
Docks & 33 & $-2,061.638$ & $4,192.505$ & 0.000 & 0.40 \\
TSI, docks & 35 & $-2,060.161$ & $4,193.957$ & 1.453 & 0.19 \\
ALK, TSI, docks & 37 & $-2,058.448$ & $4,194.965$ & 2.461 & 0.12 \\
ALK, docks & 35 & $-2,060.546$ & $4,194.727$ & 2.223 & 0.13 \\
Base & 32 & $-2,064.412$ & $4,195.859$ & 3.355 & 0.07 \\
TSI & 34 & $-2,062.601$ & $4,196.631$ & 4.127 & 0.05 \\
ALK, TSI & 36 & $-2,061.096$ & $4,198.042$ & 5.537 & 0.02 \\
ALK & 34 & $-2,063.542$ & $4,198.514$ & 6.010 & 0.02 \\
& & & & & \\
ALK, docks & 34 & $-2,306.245$ & $4,683.919$ & 0.000 & 0.55 \\
ALK & 33 & $-2,308.588$ & $4,686.404$ & 2.484 & 0.16 \\
Dock & 32 & $-2,309.807$ & $4,686.648$ & 2.729 & 0.14 \\
ALK, TSI, docks & 36 & $-2,306.262$ & $4,688.375$ & 4.455 & 0.06 \\
Base & 31 & $-2,311.818$ & $4,688.482$ & 4.563 & 0.06 \\
ALK, TSI & 35 & $-2,308.529$ & $4,690.695$ & 6.776 & 0.02 \\
TSI, docks & 34 & $-2,309.861$ & $4,691.152$ & 7.233 & 0.01 \\
TSI & 33 & $-2,311.872$ & $4,692.973$ & 9.053 & 0.01 \\
& & & & &
\end{tabular}

and emergent vegetation. Of the respondents that reported aquatic plant removal, $40 \%$ reported removal of floating-leaf plants and $44 \%$ reported removal of emergent plants; $16 \%$ of respondents noted a decline in emergent vegetation and $24 \%$ noted a decline in natural shoreline vegetation. Payton and Fulton (2004) also reported that among the respondents (76\%) with aquatic plants next to their property, $41 \%$ stated that they try to keep an area in the lake devoid of aquatic plants on a year-to-year basis to provide swimming areas and boating access and to change the appearance of the shore. Payton and Fulton (2004) and Schroeder et al. (2004), however, found that most Minnesotans believed that aquatic plants were esthetically appealing and ecologically valuable.

Alteration of natural littoral zone habitats has negative consequences for fish and wildlife. Littoral zone vegetation is important for amphibians, ducks, common loons Gavia immer, herons, and other wildlife (Meyer et al. 1997; Lindsay et al. 2002; Woodford and Meyer 2003). Floating-leaf and emergent vegetation provides fish with foraging areas and refuge from predators (Killgore et al. 1993; Casselman and Lewis 1996; Valley et al. 2004). Many fish depend on this habitat for part or most of their life (Becker 1983).
TABLE 3.-A summary of linear mixed-effects model analysis of variance, including the effect of time (periods 18), shoreland development class (general development, recreational development, natural environment), timing of photographs within year (phototime), alkalinity (ALK) group, trophic status (TSI) index group, and development (dock sites/ $\mathrm{km}$; docks) on dense-stand floating-leaf and emergent vegetative cover (percentage of lake or littoral area) in north-central Minnesota lakes. Variability between lakes was modeled by a random-effect term. Models were fit with restricted maximum likelihood.

\begin{tabular}{|c|c|c|c|}
\hline Source of variation & df & $F$ & $P$ \\
\hline \multicolumn{4}{|c|}{ Vegetative cover as percentage of lake surface area } \\
\hline \multicolumn{4}{|c|}{ Model 1} \\
\hline Time & 7, 605 & 12.413 & $<0.0001$ \\
\hline Shoreland development class & 2,95 & 0.238 & 0.7886 \\
\hline Phototime & 2,605 & 4.502 & 0.0115 \\
\hline TSI group & 2,95 & 1.978 & 0.1440 \\
\hline Docks & 1,605 & 3.121 & 0.0778 \\
\hline Time $\times$ shoreland development class & 14,605 & 4.416 & $<0.0001$ \\
\hline \multicolumn{4}{|l|}{ Model 2} \\
\hline Time & 7, 605 & 12.567 & $<0.0001$ \\
\hline Shoreland development class & 2,97 & 0.249 & 0.7801 \\
\hline Phototime & 2,605 & 4.620 & 0.0102 \\
\hline Docks & 1,605 & 3.642 & 0.0568 \\
\hline Time $\times$ shoreland development class & 14,605 & 4.483 & $<0.0001$ \\
\hline \multicolumn{4}{|c|}{ Vegetative cover as percentage of littoral area } \\
\hline \multicolumn{4}{|l|}{ Model 3} \\
\hline Time & 7,605 & 12.454 & $<0.0001$ \\
\hline Shoreland development class & 2,95 & 0.558 & 0.5742 \\
\hline Phototime & 2,605 & 3.230 & 0.0402 \\
\hline ALK & 2,95 & 2.810 & 0.0652 \\
\hline Docks & 1,605 & 2.785 & 0.0957 \\
\hline Time $\times$ shoreland development class & 14,605 & 4.338 & $<0.0001$ \\
\hline
\end{tabular}

Floating-leaf vegetation, such as white water lilies Nymphaea odorata, provides shade and overhead cover for largemouth bass Micropterus salmoides and other centrarchids. Emergent vegetation, such as hardstem bulrushes Scirpus acutus, provides spawning habitat, cover, and colonization sites for aquatic invertebrates and protects shores from erosion by dampening wave energy. Numerous fish species use protected embayments and vegetative cover disproportionately to their availability (Wei et al. 2004). Human activities that change vegetative cover can alter ecological processes and energy flow within lakes, thereby reducing their ability to support diverse and healthy fisheries (Schindler and Scheuerell 2002).

Changes in aquatic plant communities may also occur with development. Hatzenbeler et al. (2004) determined that aquatic plant communities declined with increasing lakeshore development, number of plant species per lake, and number of highly intolerant plant species per lake and that species richness and frequency of occurrence of floating-leaf vegetation was diminished on more-developed lakes. In addition, quantification of long-term changes in aquatic macrophyte communities is important in the assessment of 


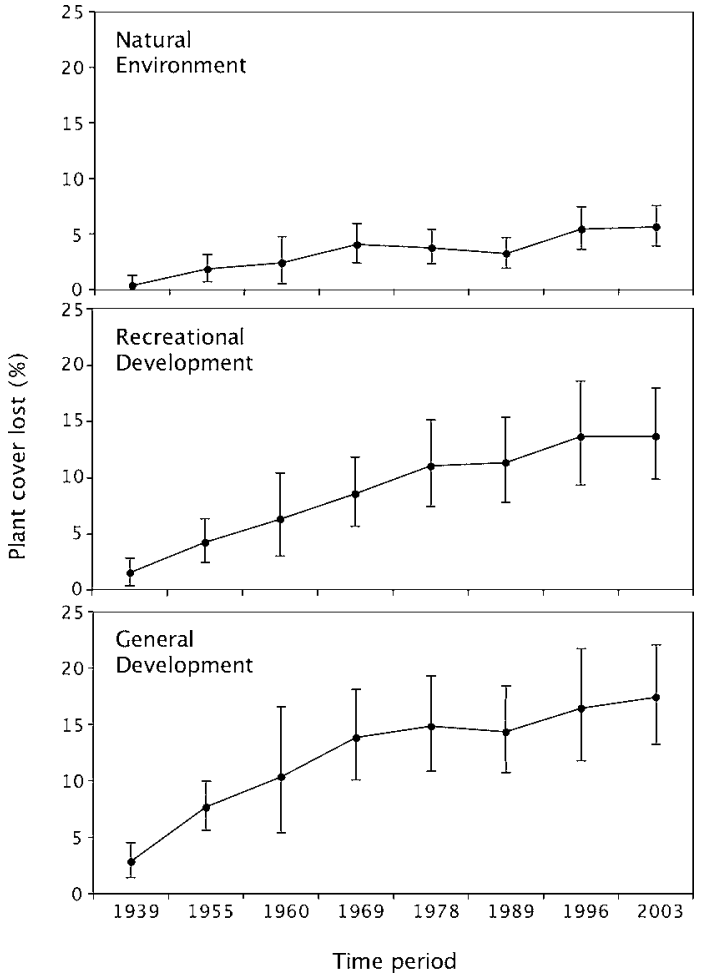

FIGURE 3.-Floating-leaf and emergent vegetative cover losses (\% of lake area) during 1939-2003 for north-central Minnesota lakes belonging to three shoreland development classes (see Table 3, model 2). Bars represent approximate $90 \%$ confidence intervals; periods are labeled with the modal year.

ecological consequences of human activities. Garrison and Wakeman (2000), using paleolimnological techniques, determined that aquatic macrophyte increases in Wisconsin lakes coincided with early shoreland development and associated increases in nutrient loading. The observed increase in mean floating-leaf and emergent vegetative cover in Minnesota's naturalenvironment lakes may be the result of a growing season increase due to climate change (Magnuson et al. 2000; Magnuson 2002). Potential increases in mean vegetative cover of recreational- and generaldevelopment lakes due to longer growing seasons appeared to be negated by increased development, which resulted in mean coverage that was either similar to or slightly lower than the earlier period. However, plant cover loss for a given lake was dependent on the amount of shoreland development. Long-term studies also give natural resource managers information on natural variability of abundance, which can be quite high for lake plant communities (Nichols 1997).

Studies on historical changes can also set resource baselines. Ramstack et al. (2004), by reconstructing

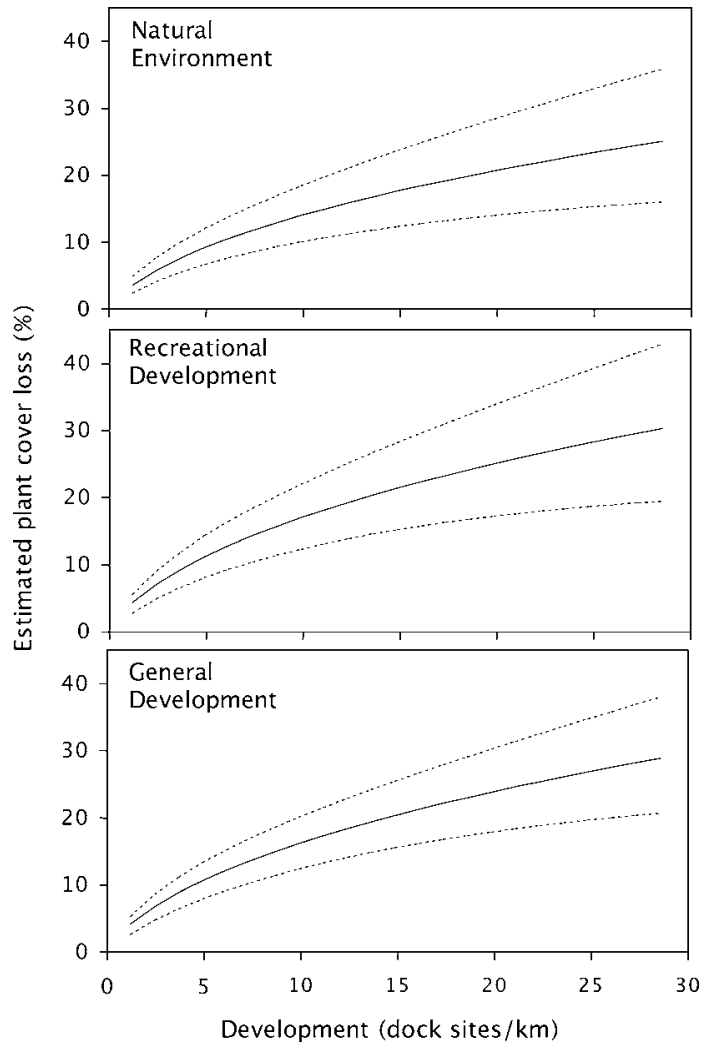

FIGURE 4.-Floating-leaf and emergent vegetation losses (\% of lake area) as a function of shoreline development for northcentral Minnesota lakes belonging to three shoreland development classes (see Table 3, model 2). Dotted lines represent approximate $90 \%$ confidence intervals, which correspond to uncertainty in the mean response.

water chemistry for 55 Minnesota lakes from sedimentary diatom assemblages, increased awareness of baseline conditions in the lakes and provided managers with advice on restoration goals. Studies on historical changes to lake vegetation could serve the same role for aquatic macrophytes. Hudon (1997) found that emergent plants covered 1-38\% of the surface area of Lake Saint-Pierre, Quebec, and that coverage increased as water levels decreased; from this relationship, Hudon estimated annual emergent vegetative coverage for the 80 prior years. Gabriel and Bodensteiner (2002) studied historical changes in abundance of the common reed Phragmites australis in Winnebago pool lakes and noted an overall decline in the size of stands, probably due to changes in water level management and other stressors, such as damage by boats and common carp Cyprinus carpio. Szajnowski (1983) found that a rapid loss of emergent plants in Polish lakes from 1958 to 1982 was attributable to removal by humans. Increased boating activity, including larger boats and personal 
watercraft, increases physical contact with plants and wave action, both of which cause increased plant damage (Ostendorp et al. 1995).

In addition to aquatic plant management regulations, shoreline development standards (e.g., regulations on lot width, buffers, and shoreland structures) may be used to reduce fish and wildlife habitat loss (Bernthal 1997). Radomski and Goeman (2001) suggested numerous policy changes, including zoning, community planning, education, and aquatic plant control regulations. Two additional suggestions are provided here. First, given the estimated plant losses to date and the projected possible future losses with further shoreland development, more restrictive development standards seem reasonable and warranted for sheltered bays and areas where dense floating-leaf and emergent plant stands are present (these often constitute a large portion of vegetative cover for a lake). Second, use of a shoreline incentive program that promotes good shoreland and shoreline management by property owners may have merit. Skinner (1987) noted that contrived reinforcements are often required to elicit good behavior, so attempts to reward people for environmentally sound management of their land may have positive consequences for others and may constitute a public resource. Such policies, together with appropriate aquatic plant management and shoreland development rules and regulations, may promote a healthy and balanced nearshore plant community. This plant community provides many environmental services to our lakes, such as absorbing nutrients that reduce water quality, reducing erosion from waves, and providing food and habitat for fish and wildlife. Perhaps as important, the native flora, more than anything else, defines the ecological character of our lakes.

\section{Acknowledgments}

I thank Kevin Page, Dan Isermann, Don Pereria, John Fieberg, Mike Duval, and Jack Wingate for advice and for reviewing earlier drafts of the manuscript. I thank Meredith Novak for compiling and scanning aerial photographs. This project was funded in part by the Federal Aid in Sport Fish Restoration (Dingell-Johnson) program. The manuscript was improved by three formal reviewers.

\section{References}

Becker, G. C. 1983. Fishes of Wisconsin. University of Wisconsin Press, Madison.

Bernthal, T. W. 1997. Effectiveness of shoreland zoning standards to meet statutory objectives: a literature review with policy implications. Wisconsin Department of Natural Resources, Publication PUBL-WT-505-97, Madison.

Burnham, K. P., and D. R. Anderson. 2002. Model selection and multimodel inference: a practical informationtheoretic approach. Springer, New York.

Byran, M. D., and D. L. Scarnecchia. 1992. Species richness, composition, and abundance of fish larvae and juveniles inhabiting natural and developed shorelines of a glacial Iowa lake. Environmental Biology of Fishes 35:329-341.

Carlson, R. E. 1977. A trophic state index for lakes. Limnology and Oceanography 22:361-369.

Casselman, J. M., and C. A. Lewis. 1996. Habitat requirements of northern pike (Esox lucius). Canadian Journal of Fisheries and Aquatic Sciences 53(Supplement 1):161174.

Christensen, D. L., B. R. Herwig, D. E. Schindler, and S. R. Carpenter. 1996. Impacts of lakeshore residential development on coarse woody debris in north temperate lakes. Ecological Applications 6:1143-1149.

Elias, J. E., and M. W. Meyer. 2003. Comparisons of undeveloped and developed shorelands, northern Wisconsin, and recommendations for restoration. Wetlands 23:800-816.

Engel, S., and J. L. Pederson, Jr. 1998. The construction, aesthetics, and effects of lakeshore development: a literature review. Wisconsin Department of Natural Resources, Research, Report 177, Madison.

Farm Services Agency. 2003. National agricultural imagery program digital orthorectified images, Minnesota, 2003. Salt Lake City, Utah.

Gabriel, A. O., and L. R. Bodensteiner. 2002. Historical changes in mid-water stands of common reed in the Winnebago pool lakes, Wisconsin. Journal of Freshwater Ecology 17:563-573.

Garrison, P. J., and R. S. Wakeman. 2000. Use of paleolimnology to document the effect of lake shore development on water quality. Journal of Paleolimnology 24:369-393.

Hatzenbeler, G. R., J. M. Kampa, M. J. Jennings, and E. E. Emmons. 2004. A comparison of fish and aquatic plant assemblages to assess ecological health of small Wisconsin lakes. Lake and Reservoir Management 20:211-218.

Hudon, C. 1997. Impact of water level fluctuations on St. Lawrence River aquatic vegetation. Canadian Journal of Fisheries and Aquatic Sciences 54:2853-2865.

Jennings, M., K. Johnson, and M. Staggs. 1996. Shoreline protection study: a report to the Wisconsin state legislature. Wisconsin Department of Natural Resources, Publication PUBL-RS-921-96, Madison.

Jennings, M. J., E. E. Emmons, G. R. Hatzenbeler, C. Edwards, and M. A. Bozek. 2003. Is littoral habitat affected by residential development and land use in watersheds of Wisconsin lakes? Lake and Reservoir Management 19:272-279.

Kelly, T., and J. Stinchfield. 1998. Lakeshore development patterns in northeast Minnesota: status and trends. Minnesota Department of Natural Resources, Office of Management and Budget Services, St. Paul.

Killgore, K. J., E. D. Dibble, and J. J. Hoover. 1993. Relationships between fish and aquatic plants: a plan of study. U.S. Army Corps of Engineers, Miscellaneous Paper A-93-1, Vicksburg, Mississippi.

Laird, N. M., and J. H. Ware. 1982. Random-effects models for longitudinal data. Biometrics 38:963-974.

Lindsay, A. R., S. S. Gillum, and M. W. Meyer. 2002. Influence of lakeshore development on breeding bird communities in a mixed northern forest. Biological Conservation 107:1-11. 
Lizardtech. 2003. GeoExpress View with MrSID by ILS. International Land Systems, Silver Spring, Maryland, and Lizardtech, Seattle.

Magnuson, J. J., D. M. Robertson, B. J. Benson, R. H. Wynne, D. M. Livingstone, T. Arai, R. Assel, R. G. Barry, V. Card, E. Kuusisto, N. G. Granin, T. D. Prowse, K. M Stewart, and V. S. Vuglinski. 2000. Historical trends in lake and river ice cover in the northern hemisphere. Science 289:1743-1746.

Magnuson, J. J. 2002. Signals from ice cover trends and variability. Pages 3-14 in N. A. McGinn, editor. Fisheries in a changing climate. American Fisheries Society, Symposium 32, Bethesda, Maryland.

Meyer, M., J. Woodford, S. Gillum, and T. Daulton. 1997. Shoreland zoning regulations do not adequately protect wildlife habitat in northern Wisconsin. U.S. Fish and Wildlife Service, State Partnership Grant P-1-W, Segment 17, Final Report, Madison, Wisconsin.

MNDNR (Minnesota Department of Natural Resources). 1989. Shoreland management standards: statement of need and reasonableness. MNDNR, St. Paul.

Moyle, J. B. 1945. Some chemical factors influencing the distribution of aquatic plants in Minnesota. American Midland Naturalist 34:402-420.

Moyle, J. B. 1956. Relationships between the chemistry of Minnesota surface waters and wildlife management. Journal of Wildlife Management 20:303-320.

Nichols, S. A. 1997. Seasonal and sampling variability in some Wisconsin lake plant communities. Journal of Freshwater Biology 12:173-182.

Ostendorp, W., C. Iscli, M. Krauss, P. Krumscheid-Plankert, J. L. Moret, M. Rollier, and F. Schanz. 1995. Lake shore deterioration, reed management and bank restoration in some Central European lakes. Ecological Engineering 5:51-75.

Payton, M. A., and D. C. Fulton. 2004. A study of landowner perceptions and opinions of aquatic plant management in Minnesota lakes. U.S. Geological Survey, Minnesota Cooperative Fish and Wildlife Research Unit, University of Minnesota, Department of Fisheries, Wildlife, and Conservation Biology, St. Paul.

Pinheiro, J. C., and D. M. Bates. 2000. Mixed-effects models in S and S-PLUS. Springer-Verlag, New York.

R Development Core Team. 2005. R: a language and environment for statistical computing. R Foundation for Statistical Computing, Vienna, Austria. Available: www. r-project.org. (March 2005).

Radomski, P., and T. J. Goeman. 2001. Consequences of human lakeshore development on emergent and floatingleaf vegetation abundance. North American Journal of Fisheries Management 21:46-61.

Ramstack, J. M., S. C. Fritz, and D. R. Engstrom. 2004. Twentieth century water quality trends in Minnesota lakes compared with presettlement variability. Canadian Journal of Fisheries and Aquatic Sciences 61:561-576.

Richards, J. A. 1993. Remote sensing digital image analysis. Springer-Verlag, New York.

SAS. 2002. JMP statistics and graphics guide, version 5. SAS Institute, Inc., Cary, North Carolina.

Schindler, D. E., and M. D. Scheuerell. 2002. Habitat coupling in lake ecosystems. Oikos 98:177-189.

Schroeder, S., M. A. Payton, and D. C. Fulton. 2004. A study of the general public's perceptions and opinions of lake and aquatic management in Minnesota. U.S. Geological Survey, Minnesota Cooperative Fish and Wildlife Research Unit, University of Minnesota, Department of Fisheries, Wildlife, and Conservation Biology, St. Paul.

Skinner, B. F. 1987. Upon further reflection. Prentice-Hall, Englewood Cliffs, New Jersey.

Szajnowski, F. 1983. Biotic structure and processes in the lake system of R. Jorka watershed (Masurian Lakeland, Poland) XI. Biomass and distribution of emergent macrophytes. Ekologia Polska 31:793-800.

University of Minnesota. 2003. Minnesota air photoguide. John R. Borchert Map Library, University of Minnesota, Minneapolis.

Valley, R. D., T. K. Cross, and P. Radomski. 2004. The role of submersed aquatic vegetation as habitat for fish in Minnesota lakes, including the implications of non-native plant invasions and their management. Minnesota Department of Natural Resources, Special Publication 160, St. Paul.

Wei, A., P. Chow-Fraser, and D. Albert. 2004. Influence of shoreline features on fish distribution in the Laurentian Great Lakes. Canadian Journal of Fisheries and Aquatic Sciences 61:1113-1123.

Wolfinger, R. D., and M. Chang. 1995. Comparing the SAS GLM and MIXED procedures for repeated measures. Proceedings of the Twentieth Annual SAS Users Group Conference. SAS Institute, Cary, North Carolina.

Woodford, J. E., and M. W. Meyer. 2003. Impact of lakeshore development on green frog abundance. Biological Conservation 110:277-284

Zar, J. H. 1999. Biostatistical analysis. Prentice-Hall, Englewood Cliffs, New Jersey.

\section{Appendix: Linear Mixed-Effects Model Used in Analysis of Lake Vegetation Abundance}

The $\mathrm{R}$ code for the preferred linear mixed-effects (lme) model to predict percent vegetative cover (tvegetation [transformed]) using the observed data set (vegdata) is as follows:

Preferred model $<-$ lme\{tvegetation $\sim$ time + scgroup + phototime + (time $\times$ scgroup $)+$ tdockperkm, random $=\sim 1$ lake, correlation $=$ corCAR1(form $=\sim$ time), data $=$ vegdata, na.action $=$ na.omit, weights $=$ varPower $[$ form $=\sim$ fitted(.) scgroup]\},

where influence of period (time), shoreland develop- ment class (scgroup), and timing of photographs (phototime) were analyzed as fixed effects. "Dock sites per shoreline kilometer (tdockperkm [transformed])" was added as a linear effect, and lake was used as the repeated-measures variable. The correlation structure class corCAR1 represents an autocorrelation structure of order 1 with a continuous time covariate. Setting na.action $=$ na.omit allows the model to be fitted by omitting cases that have missing components, and varPower specifies a model in which the variance increases with the fitted values. 